\title{
Research on the Coordinated Development Mode of University Library and Local Culture Construction
}

\author{
Zhao Fengtao \\ $X i$ 'an Peihua University, Shaanxi, China, 710125
}

Keywords: local cultural construction; cultural services; university library construction; local literature

\begin{abstract}
The construction and development of local culture marks the local economic construction. The role, advantages and important functions of local university libraries in the construction of local culture explain the importance of local cultural construction in local development, and the cultural construction of university libraries also proposes that local cultural construction needs to be strengthened. Construction of document reading room and special collection room. Large-scale development of cultural resources in the localities and provision of corresponding cultural services. We provide services to the people in need of the society, play a cultural display function, and carry out certain cultural exchange activities according to the society and people's lifestyles, so as to better provide regional cultural construction services.
\end{abstract}

\section{Introduction}

Regional culture is a geography and humanities discipline that people use to study the spatial combination of human culture. This kind of discipline is mainly based on the cultural field. And in-depth discussion of some of the life forms of people in nature., the unique regional characteristics of the cultural region, the relationship between the environment and culture, the route of cultural communication and the basic trend of development to human beings, including some folk traditions and cultural systems such as religious beliefs, such as culture and art and social organizations. . The so-called local university library refers to the library of the university affiliated to the locality. This kind of library has a very important influence on the regional cultural construction[1].

\section{The importance of local libraries in the construction of regional culture}

Different countries have different regional cultures, and different regions have their own different cultural characteristics. With the rapid development of the times and economy, different regions are trying to tap their own cultural characteristics and explore the culture. Carry out construction and build a service culture construction platform. For the development of civilization, cities and culture occupy an important position. Culture is therefore a reaction of a country's economy and status. Gradually become an important part of a country's comprehensive strength of development. Therefore, the composition and dissemination of culture is a basic principle that 
connects the peaceful coexistence of nations. As a special institution for the development of urban culture, the construction of university libraries plays an important role in the development of urban culture. However, the construction of university libraries needs to consume a lot of money. Therefore, it is a difficult thing to establish a public library for some municipal and county-level regions with insufficient economic development. Therefore, due to the influence of local finances, too little investment in the literature has resulted in relatively few people purchasing and reading each year. In order to save some people only rely on the free opening of newspapers to read. On the other hand, as the price of books continues to rise, the library's collection of documents is gradually reduced. The characteristics that need to be established are constantly being exploited. The problem of continuous faults has occurred, and the system and integrity have been destroyed. . This also caused the library to be severely persecuted for the collection of document quality. There is also an unreasonable phenomenon for the lack of modern equipment technology configuration for the library built at the municipal level. The overall quality is relatively poor, and there are some middle and senior professional technicians. As a result, management techniques are not relevant and readers' reading appeal is reduced. As a result, a large number of readers have lost their interest, and the guarantee role of the literature is difficult to play, and the social functions that exist are gradually shrinking until they face death. Therefore, the current situation and the rise of cultural areas in China have a certain difference, and can not meet the needs of cultural construction services required in local areas. In some places in China, there are more than 500,000 books in the university library, plus rich electronic, network resources and the unique resources of the university library. This kind of professionalism, reading room with local cultural characteristics, can provide a certain amount of development energy for local cultural construction. Therefore, in the construction of regional culture, university libraries have positive development of culture. Influence[2].

\section{The significance of the development of local library construction}

\subsection{Improve influence}

In the local construction of the library, this is an intangible asset of local species. Through the construction of local libraries, local cultural construction can help people understand the construction services of regional culture more deeply. Deepen people's understanding of social colleges and universities. This approach is an influential propaganda, therefore. This has attracted more people to pay attention to the construction and development of regional culture, and also attracted more social forces to the development and construction of resource libraries. The attitude of the public towards the library is as follows.

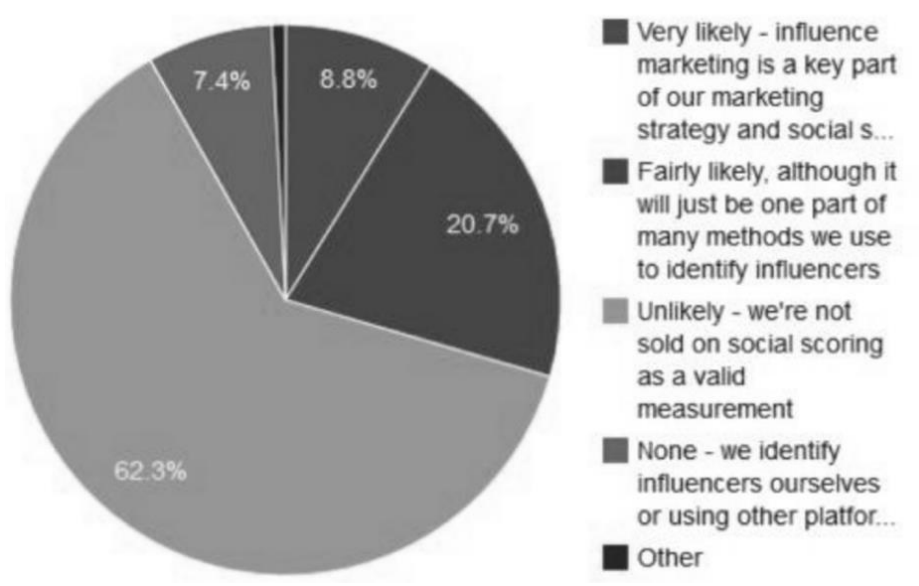

Fig.1 Attitude of the public towards the library 


\subsection{Can improve the utilization of library resources}

The development of the library not only affects the local cultural construction, but also enhances the utilization of resources in the library, improves the overall quality of the administrator, and displays the resources and related information of the library to demonstrate the role of the literature resources. Timely replenishment of missing resources. While improving the quality of books, it also adds to the characteristics of the library. It is also an improvement of the ability for the administrator to upgrade the original administrator to face the student only in a single way.

\subsection{Promote academic research results}

When the research results of the college and the regional culture are combined to form a kind of cooperation, it is necessary to establish a common reading room to promote the common development of the literature. At the same time, it can also promote the production of local cultural research results. By tapping local cultural resources, administrators can appropriately add resources to local cultural courses to improve the depth and breadth of cultural construction[3].

\section{Measures taken by local university libraries to serve local cultural construction}

\subsection{Strengthen management construction}

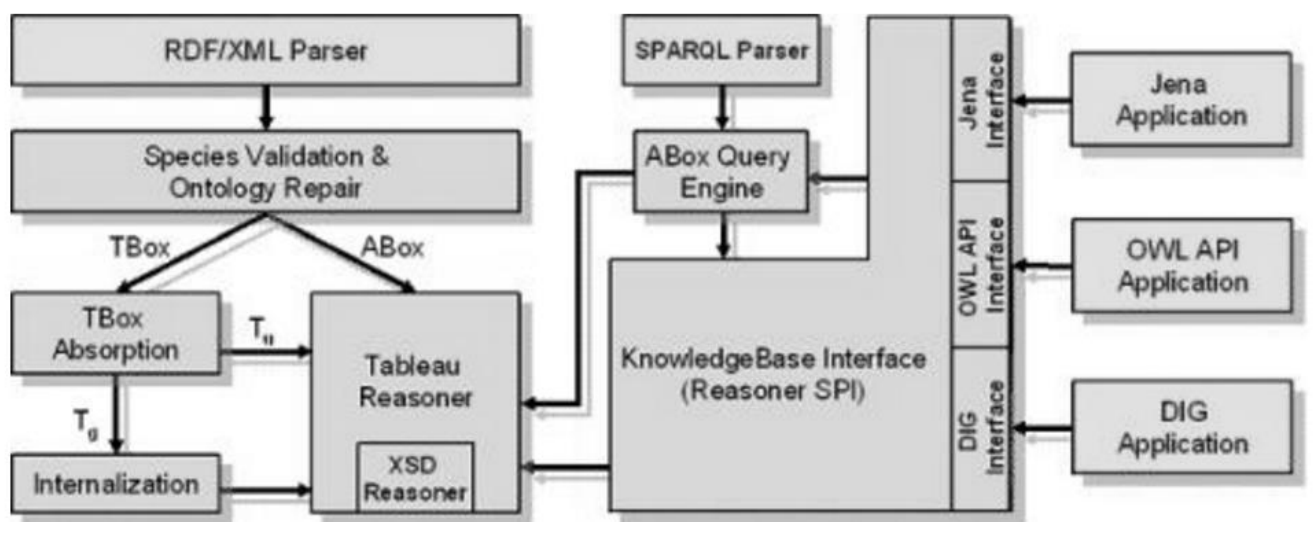

Fig.2 Library information management system model

For the construction of local culture, the construction of local libraries is very important. In order to better serve the construction of local culture, local colleges and universities can set up a relatively close professional economy in the corresponding cultural construction, in order to cultivate more On the other hand, talents in this profession can also cultivate more local economic and cultural projects related to scientific research in order to obtain strong support from local governments or local enterprises. Therefore, for local university libraries, "local" can Effectively promote the cultural development of the place, and promote the teaching quality and scientific research of the university as well as the regional cultural construction services. It is also possible to build a university library into a document information center in the region. Give full play to the important value in this region. On the other hand, the so-called "local" literature consists of two parts: the first is the profession, the literature content required by the discipline, and the knowledge scope of the "professional" literature. This kind of literature knowledge is undoubtedly the construction of university libraries. A major feature. The second is the "local literature". This local literature covers a wide range. It has the functions of recording the past and present political, economic, and cultural, educational and geographical thoughts of a region and the corresponding customs and customs. The 
main characteristics of the local literature in the library collection can be expressed as the following: history, ambition, and spectrum of the first place. Second: the general situation of the place, the third: the corresponding character situation, the fourth, the character information of the region, the fifth: the relevant local characteristics and industrial pillars, and the sixth, the resource management of tourism culture. These have reasonable plans in local university libraries, and managers will establish certain links with specialized industry departments and related cultural departments. The library information management system model is as follows.

\subsection{Research on the indispensable excavation and development of local culture}

To build a regional culture, the first thing to do is to develop and integrate the library's information and information. When the library's literature and materials become a corresponding productivity, promote the production and development of local culture. Secondly, the local university libraries should actively participate in the activities of local cultural construction. Transform traditional passive cultural propaganda into active cultural exchanges. Change "shou" to "attack" through this form to establish a platform for communication and exchange with local cultural economy. Form a cooperative relationship and seek development in collaboration and competition. And establish a relevant cultural industry survey and expert portfolio, do expert surveys and documentation records[4].

\subsection{Establish a local literature database}

Establish a local literature database to achieve real resource sharing. This kind of resource sharing is based on the economy and requires a good environment for the library. The ability to increase the level of sharing and avoid the construction of regional cultures is generally constrained.

\section{Summary}

The development of local university libraries has made certain contributions to local cultural architecture, which has promoted the development of local culture more quickly. On the other hand, it has established local culture and local university libraries, and has also established a Convenient and efficient information resource service system.

\section{References}

[1] Thomas Hill. The 'Library Café': distributing and archiving local culture through a podcast library interview program[J]. Art Libraries Journal,2010,35(3).

[2] Martins, Ana Bela, Marques, Alexandra. Promoting a reading culture in school community: how to engage reading activities cross curricula, directors, teachers, students, parents, administrative services, local authorities, public libraries and other partners - Relating a project[J]. International Association of School Librarianship. Selected Papers from the ... Annual Conference,2010.

[3] Ying ZENG. Analysis of How the Local University Library to Service for the New Rural Culture Construction[J]. Cross-Cultural Communication,2015,11(11).

[4] Peng, Peng-Shun, Shieh, Jiann-Cherng. School libraries archive community images[J]. International Association of School Librarianship. Selected Papers from the ... Annual Conference,2009. 